\title{
Biologically Active Compounds and Antioxidant Activity of the Plants from CSBG SB RAS Collection of the Rosaceae Family (I)
}

\author{
Elena Khramova $^{1 *}$, Tatyana Kukushkina ${ }^{1}$, Tatyana Shaldaeva $^{1}$, Yuliya Pshenichkina ${ }^{1}$, and \\ Galina. Vysochina ${ }^{1}$ \\ ${ }^{1}$ Central Siberian Botanical Garden SB RAS, 630090 ul. Zolotodolinskaya, 101, Novosibirsk, Russia
}

\begin{abstract}
The article presents Dara on the content of biologically active compounds (BAC) and the total phenolic antioxidants activity (TPA) evaluated for leaves and inflorescences of eight species from the Rosaceae family: Padus avium, Malus baccata, Alhemilla vulgaris, Potentilla inquinans, Filipendula vulgaris, F. palmata, Sanguisorba officinalis, S. alpina. It was determined that leaves and inflorescences contain flavonols, catechins, tannins, carotenoids, saponins, pectin substances. Usually, woody plants tend to accumulate less BAC and TPA than herbs. The highest level of flavonols and tannins was registered in inflorescences of $F$. vulgaris $(12.25 \%$ and $45.02 \%)$. The content of pectin substances was quite high, with the biggest share of protopectins (4.4-10.65\%). The maximum quantity of catechins $(4.76 \%)$ was found in the leaves of $F$. palmata, saponins - in the inflorescences of M. baccata (20.77\%). The highest content of carotenoids was found in the leaves of plants, most notably in P. inquinans $(1.00 \mathrm{mg} / \mathrm{g})$. The highest antioxidant activity was recorded for water-ethanol extracts from inflorescences (up to $7.77 \mathrm{mg} / \mathrm{g}$ ) and leaves $(2.11 \mathrm{mg} / \mathrm{g}$ ) of $F$. vulgaris and A. vulgaris plants due to increased content of phenolic compounds, in particular flavonols and tannins, compared to the other species.
\end{abstract}

The Rosaceae is one of the leading and most diverse families due to its species variety [1]. This family includes ornamental and valuable medicinal plants as well as edible fruits and berries of high economic importance. Different life forms of plants are presented in the Rosaceae collection of CSBG, i.e., trees, shrubs and herbs. Padus avium Mill. and Malus baccata (L.) Borkh. are deciduous trees or shrubs. Perennial herbs are represented in the collection by Alhemilla vulgaris L., Potentilla inquinans Turcz and few species of two genera: Filipendula (Filipendula vulgaris Moench. and F. palmata (Pall.) Maxim. and Sanguisorba (Sanguisorba officinalis L. and S. alpina Bunge). These plants, excepting such species as $P$. inquinans and $S$. alpina, have sufficient raw material base to be used in both orthodox and folk medicine, they also show encouraging results in experimental studies on various types of activity. At the same time, data on the chemical composition of the selected plants are still fragmentary [2-3]. The most detailed studies of biochemical composition and, in particular, of the phenolic complex were made for A. vulgaris, $S$. officinalis and F. vulgaris [4-8]. As for other plants, there are no data available. Moreover, researches on the antioxidant activity of plants is of a growing interest nowadays.

\footnotetext{
* Corresponding author: khramova@ngs.ru
} 
The purpose of this research was a comparative study of the content of biologically active compounds and the total activity of phenolic antioxidants in leaves and inflorescences of Rosaceae plants, successfully introduced in CSBG SB RAS.

\section{Materials and Methods}

The materials were selected from plants cultivated on the introduction plot of the CSBG during the flowering phase in 2019. The raw materials were divided into leaves and inflorescences, dried and crushed to pick representative sample for analysis.

The detection of flavonols was performed by a spectrophotometric method [9]. The content of catechins was detected by the method based on the ability of catechins to give crimson staining with a solution of vanillin in concentrated hydrochloric acid [10]. Detection of tannins (hydrolyzable tannins) was performed using a spectrophotometric method [11]. The content of carotenoids was detected in acetone-ethanol extraction [12-13]. Pectin substances (pectins and protopectins) were determined by a carbazole-free method based on obtaining a specific yellow-orange staining of uronic acids with thymol in a sulfuric acid medium [14]. The content of saponins was detected by weight method [15]. To detect the total activity of phenol-type antioxidants, an operational amperometric method was used [16]. The measurements were performed on the device "Tsvet Jauza-01AA". Before the measurement, calibration curve was constructed to determine dependence of the signal of comparison sample (Gallic acid) on its concentration. All biochemical parameters were calculated for the mass of absolutely dry raw materials.

Detection of the content of BAC was carried out in threefold repetition, TPA - in fivefold. Statistical data processing was based on descriptive statistics using Statistica 8.0 and Microsoft Excel 2010 programs.

\section{Results and Discussion}

It was found that leaves and inflorescences of the plants contain a complex of biologically active substances.

Leaves and inflorescences of the plants contained flavonols, tannins and catechins. Their content varied depending on the type and organ of the plant (Table 1). The content of flavonols in inflorescences was usually higher than in leaves, while tannins and catechins content, on the contrary, was higher in leaves.

Table 1. The content of phenolic compounds in aboveground organs of plants (\% d.m.)

\begin{tabular}{|l|c|c|c|c|c|c|}
\hline \multicolumn{1}{|c|}{ Plants } & \multicolumn{2}{|c|}{ Flavonols } & \multicolumn{2}{c|}{ Tanins } & \multicolumn{2}{c|}{ Catechins } \\
\hline & $\mathrm{L}$ & $\mathrm{I}$ & $\mathrm{L}$ & $\mathrm{I}$ & $\mathrm{L}$ & $\mathrm{I}$ \\
\hline Padus avium & 3.41 & 4.49 & 14.65 & 11.99 & 0.81 & 0.5 \\
\hline Malus baccata & 2.47 & 2.25 & 16.74 & 8.76 & 0.09 & 0.15 \\
\hline Alhemilla vulgaris & 4.25 & 5.63 & 20.66 & 26.4 & 0.17 & 0.14 \\
\hline Potentilla inquinans & 3.14 & 6.77 & 20.86 & 22.71 & 0.15 & 0.21 \\
\hline Filipendula vulgaris & 1.89 & 12.25 & 21.16 & 45.02 & 1.4 & 0.25 \\
\hline Filipendula palmata & 2.76 & 4.58 & 20.13 & 31.78 & 4.76 & 0.4 \\
\hline Sanguisorba officinalis & 1.14 & 0.78 & 8.85 & 12.99 & 0.12 & 0.66 \\
\hline Sanguisorba alpina & 5.74 & 1.53 & 15.16 & 12.53 & 0.15 & 2.44 \\
\hline
\end{tabular}

L - leaves, I - inflorescences

Two types of Filipendula showed significant tannin content from 20.13-21.16 \% in leaves to $31.78-45.02 \%$ in inflorescences. In addition, inflorescences of F.vulgaris accumulated up to $12.25 \%$ of flavonols. A minimum of flavonols and tannins were found 
in leaves and inflorescences of $S$. officinalis. The highest content of catechins was observed in leaves of $F$. palmata (4.76\%) and inflorescences of S. alpina $(2.44 \%)$. In general, woody plants accumulated less phenolic compounds than herbs.

Pectin substances (or pectin) belong to a group of plant polysaccharides, which exist in plant cell walls, contribute to the turgor maintenance in them, increase drought resistance of plants, play an important role in protecting tissues from vegetative pathogens and injury, show a wide range of physiological activity [17, 18]. Pectin substances in the form of water-insoluble compounds are known as protopectins. The content of pectin substances in the studied plants was quite high with the main share of protopectins in the total substances (Fig. 1).

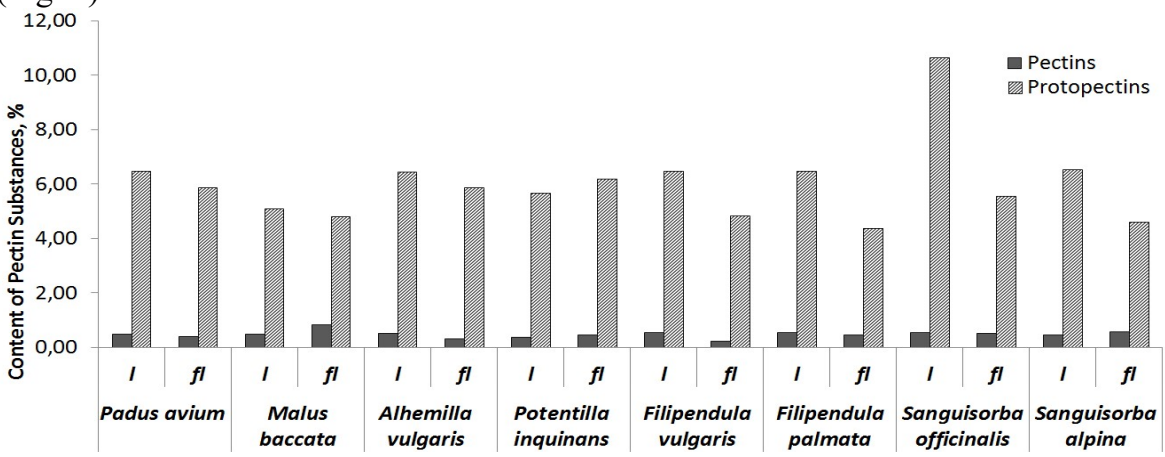

Fig. 1. Contents of pectin substances in aboveground organs of plants (1 - leaves, $\mathrm{fl}$ - inflorescences)

The content of pectins in plant leaves and protopectins in inflorescences of eight taxa varied at a low level, the coefficient of variation $(\mathrm{Cv})$ is $12-13 \%$. At the same time, the content of protopectins in leaves and pectins in inflorescences varied in a wide range, the variability was estimated as medium and high $(\mathrm{Cv}=25-39 \%)$. Remarkably, significant accumulation of protopectins was detrmined for leaves of S. officinalis (10.65\%), and pectins - for inflorescences of Malus baccata $(0.84 \%)$.

Saponins are secondary metabolites of glycosidic nature, they are widely distributed in higher plants, have surface and hemolytic activity as well as toxicity toward cold-blooded [19]. The content of saponins in leaves and inflorescences of plants of the studied species varied in a wide range, the variability of saponins was estimated as very high $(\mathrm{Cv}=59$ $79 \%$ ). The content of saponins in leaves and inflorescences of woody plants was higher than in herbaceous species, except for the leaves of $S$. alpine plants, which had the maximum accumulation of these compounds (15.56\%) (Fig. 2).

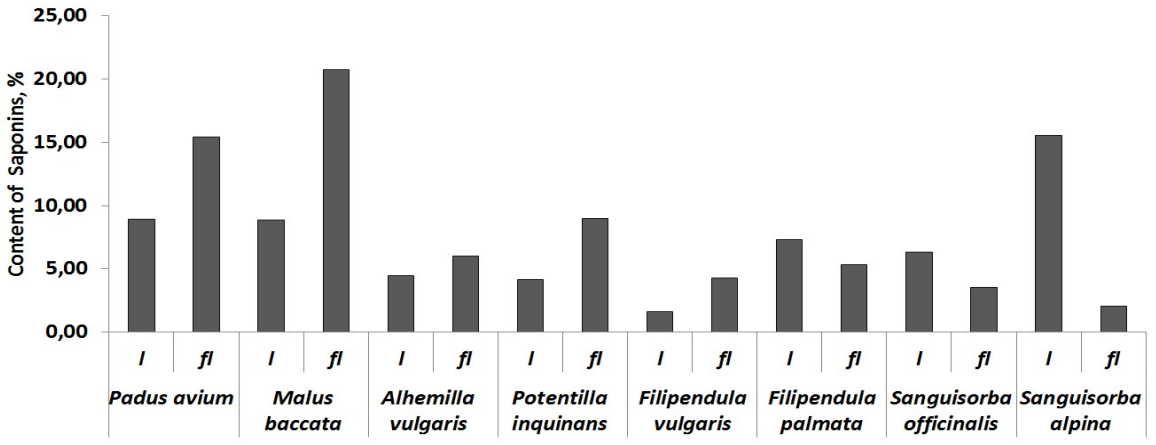

Fig. 2. Content of saponins in in aboveground organs of plants ( 1 - leaves, $\mathrm{fl}$ - inflorescences)

The highest content of saponins in inflorescences was identified for Malus baccata $(20.77 \%)$. 
Carotenoids play an important role in photosynthesis, in protection from the harmful effects of UV radiation, and make a certain contribution to the color of tissues containing them. According to our data, content of carotenoids was higher in leaves than in inflorescences, regardless of the plant species (Fig. 3), which is quite consistent with data for other species [20].

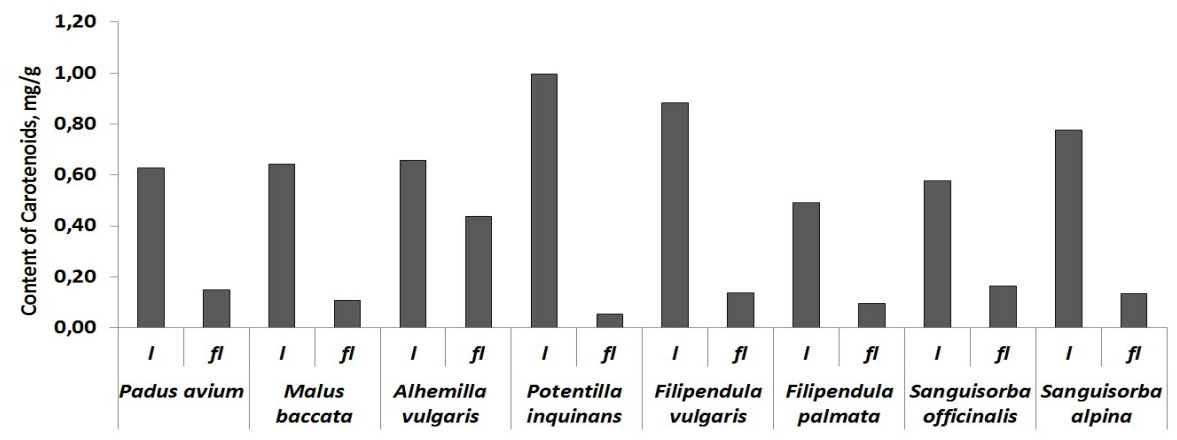

Fig. 3. Content of carotenoids in in aboveground organs of plants ( 1 - leaves, $\mathrm{fl}$ - inflorescences)

The highest accumulation of carotenoids $(0.78-1.00 \mathrm{mg} / \mathrm{g})$ was notably observed in leaves of $P$. inquinans, $F$. vulgaris and $S$. alpina. The minimum content of carotenoids in leaves was found for F. palmata $(0.49 \%)$, in inflorescences - for P. inquinans $(0.06 \mathrm{mg} / \mathrm{g})$.

The research evaluated the total antioxidant activity of water-alcohol extracts from leaves and inflorescences of the studied plants. It was found that the samples exhibit different antioxidant activity (Fig. 4).

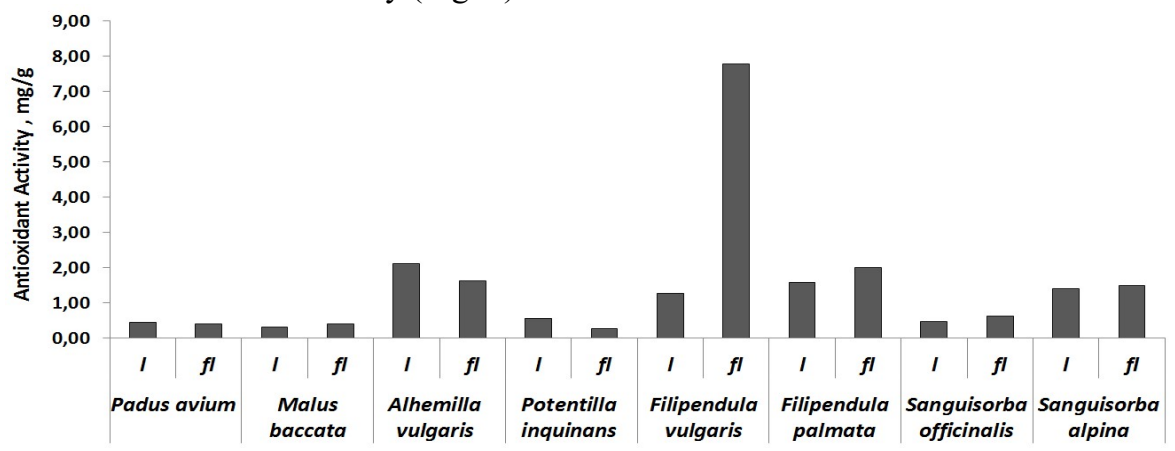

Fig. 4. Total antioxidant content in aboveground organs of plants ( 1 - leaves, $\mathrm{fl}$ - inflorescences).

High antioxidant activity was shown by plants of Filipendula, A. vulgaris and S. alpina. The maximum total content of antioxidants was found in the inflorescences of $F$. vulgaris (7.77 \%). Notably, for the species of Filipendula and Sanguisorba, the antioxidant activity in the inflorescences was higher than in the leaves. Woody plants had lower antioxidant activity than herbs. High antioxidant activity of inflorescences and leaves of plants for two species, Filipendula and Alhemilla vulgaris, is associated with an increased content of phenolic compounds (flavonols, tannins) in these samples. Analyzing the correlation between the content of BAC in leaves and inflorescences of the studied plants with antioxidant activity, performed by the method of correlation analysis, it was determined that flavonols and tannins are most closely associated with anti-oxidant activity $(\mathrm{R}=0.8)$ (table 2), that is supported by literature data for other plant species [21].

Table 2. Spearman's correlation coefficients (R) for anti-oxidant activity 


\begin{tabular}{|c|c|c|c|c|c|c|c|}
\hline & Flavonols & Tanins & Catechin & Pectins & Protopectins & Carotenoids & Saponins \\
\hline $\mathrm{R}$ & $\mathbf{0 , 7 8}$ & $\mathbf{0 , 8 2}$ & 0,00 & $\mathbf{- 0 , 5 3}$ & $-0,26$ & $-0,21$ & $-0,30$ \\
\hline
\end{tabular}

Marked correlations are significant at $\mathrm{p}<0.05$

The research was carried out in the framework of the state task for the project No. AAAA17117012610051-5 using the collection of living plants of CSBG SB RAS USU 440534.

\section{References}

1. The Plant List, Version 1.1. (2013) Published on the Internet; http://www.theplantlist.org/

2. Yu.V. Zagurskaya, O.V. Kotsupiy, T.I. Siromlya, Plant Life of Asian Russia, 4,102107 (2018)

3. E.V. Ivanova, V.N. Sorokopudov, O.A. Sorokopudova, Modern problems of science and education, 4, 499 (2014)

4. V.Yu. Andreeva, G.I. Kalinkina, Plant chemistry, 2, 79-85 (2000)

5. J. Katanić, E-M. Pferschy-Wenzig, V. Mihailović, Food and Chemical Toxicology, 122, 151-162 (2018)

6. E.A. Krasnov, E.Yu. Avdeeva, Plant chemistry, 4, 5-12 (2012)

7. A. Gawron-Gzella, E. Witkowska-Banaszczak, W. Bylka, Pharmaceutical Chemistry Journal, 50, 244-249 (2016)

8. S. Marchyshyn, V. Kudrja, O. Zarichanska, The Pharma Innovation Journal, 6, 274277 (2017)

9. V.V. Belikov, Farmatsiya, 1, 66-72 (1970)

10. T.A. Kukushkina, A.A. Zykov, L.A. Obukhova, Manzhetka obyknovennaya (Alchemila vulgaris) kak istochnik lekarstvennyh sredstv, in Proceedings of the VII International Congress on Actual problems of creating new drugs of natural origin, 3-5 Yuly 2003, St. Petersburg, Russia (2003)

11. L.M. Fedoseyeva, Plant chemistry, 2, 45-50 (2005)

12. V.I. Kriventsov, Methodological recommendations for the analysis of fruits for biochemical composition (Yalta, 1982)

13. A.I. Ermakov, Methods of biochemical study of plants, (Leningrad, 1987)

14. V.I. Kriventsov, Works of the Nikitsky Botanical Garden, 109, 128-137 (1989)

15. A.V. Kiseleva, T.A.Volkhonskaya, V.Ye. Kiselev, Biologically active substances of medicinal plants in Southern Siberia, (Novosibirsk, 1991)

16. P.A. Fedina, A.Ya.Yashin, N. I. Chernousova, Plant chemistry, 2, 91-97 (2010)

17. A.G.J. Voragen, G.-J. Coenen, R.P. Verhoef, H.A. Schols, Struct. Chem., 20, 263-275 (2009)

18. Yu.S. Ovodov, Russian Journal of Bioorganic Chemistry, 35, 293-310 (2009)

19. I. Podolak, A. Galanty, D. Sobolewska, Phytochem Rev., 9, 425-474 (2010)

20. V.I. Deyneka, A.A. Shaposhnikov, L.A. Deyneka, et al., Scientific bulletins of Belgorod State University. Series: Medicine. Pharmacia, 46, 19-25 (2008) 
21. G.N. Chupakhina, P.V. Maslennikov, L.N. Skrypnik, N.Yu. Chupakhina, P.V. Fedurayev. Antioxidant properties of cultivated plants of the Kaliningrad region, (Kaliningrad, 2016) 